This is the final draft, after peer-review, of a manuscript published in Clinical Ethics. The definitive version, detailed above, is available online at www.rsmjournals.com.

\title{
Competent minors and health care research: autonomy does not rule, okay?
}

\begin{abstract}
A dearth of clinical research involving children has resulted in off license and sometimes inappropriate medications being prescribed to the paediatric population. In this environment, recent years have seen the introduction of a raft of regulation aimed at increasing the involvement of children in clinical trials research and generating evidenced based medicinal preparations for their use. However, this regulation pays scant attention to the autonomy of competent minors. In particular, it makes no provision for the ability of competent minors to consent to participate in medical research and is therefore at odds with best ethical practice. This article explores the tensions between law and ethics in relation to clinical research involving minors and concludes that greater respect should be given to the autonomy of those who are competent to decide for themselves.
\end{abstract}

\section{Introduction/Background}

In the past children have often been the victims of research abuses. ${ }^{1}$ Their physical frailty, immaturity, and limited ability to exercise individual autonomy makes them especially vulnerable, particularly in their early years. Consequently, real concerns arise about exposing children to the risks associated with medical research, and this has resulted in a profound reluctance to conduct trials involving children. ${ }^{2}$ However, the historical failure to involve children in clinical research and trials of medicinal products means that many of the treatments prescribed to children are not supported by validated clinical evidence. ${ }^{3}$ Drugs designed for use in adults and not licensed for paediatric use are frequently

\footnotetext{
${ }^{1}$ Shamoo AE, Resnik DB, Responsible Conduct of Research, London: OUP, 2003: 186-191

${ }^{2}$ Caldwell PHY, Murphy SB, Butow PN,. Clinical Trials in Children. The Lancet 2004; 364: 803-11

${ }^{3}$ Rudolph M , A search for the evidence supporting community paediatric Practice. Archives of Disease Childhood 1999; 80: 257, Conroy S, Choonara I, Impicciatore P, et al, Survey of unlicensed and off-label drug use in paediatric wards in European countries. BMJ 2000; 322: 79-82, Smyth RL, Research with Children. BMJ 2001; 322: 1444-48
} 
prescribed to children 'off label' for want of child specific preparations. This is despite the fact that children's physiology is different to that of adults and alters with their physical development, which has sometimes led to the implementation of ineffective, or perhaps even harmful, treatment regimes. ${ }^{4}$

The paucity of research involving children has occurred despite the fact that ethical guidelines have long recognised its importance. For example, in 1964 the World Health Organisation's Declaration of Helsinki endorsed research in vulnerable populations, including children, if 'the research is necessary to promote the health of the population represented and ... cannot instead be performed on legally competent persons'. Guidelines such as this have been highly influential in shaping the law and regulation that governs clinical research in the UK today. For instance, the Helsinki principles are evident in the European Clinical Trials Directive $2001 / E C / 20$, which regulates clinical trials of investigational medicinal products and was transposed into UK law by the Clinical Trials Regulations $2004 .{ }^{5}$ The Directive also reflects, and explicitly acknowledges, increasing concerns about the failure to involve children in research, ${ }^{6}$ with Paragraph 3 of its preamble stating that:

there is a need for clinical trials involving children to improve the treatment available to them. Children represent a vulnerable population with developmental, physiological and psychological differences from adults, which make age - and development - related research important for their benefit.

With this in mind the European Regulation No 1901/2006 on medicinal products for paediatric use came into force in January $2007 .{ }^{7}$ Its central aim is to to improve the information available on the use of medicinal products in the various paediatric populations', ${ }^{8}$ and it is designed to facilitate paediatric trials which seek to give children greater access to medicines that have been specifically designed or adapted and licensed for their use. Such trials must be performed in compliance with the European

\footnotetext{
${ }^{4}$ Mulhall A, De Louvois J, Hurley R, Chloramphenicol Toxicity in Neonates: Its Incidence and Prevention. BMJ (Clin Red Ed) 1983; 287: 1424-27

${ }^{5}$ Medicines for Human Use (Clinical Trials) Regulations 2004, SI 2004 No. 1031.

${ }^{6}$ Caldwell PHY, Murphy SB, Butow PN, et al, Clinical Trials in Children. The Lancet 2004; 364: 803-11

7 Regulation (EC) No $1901 / 2006$ of the European Parliament and of the Council of 12 December 2006 on medicinal products for paediatric use and amending Regulation (EEC) No 1768/92, Directive 2001/20/EC, Directive 2001/83/EC and Regulation (EC) No 726/2004.

${ }^{8}$ European Regulation No 1901/2006 Preamble, para. 4.
} 
Directive, and must not subject 'the paediatric population to unnecessary clinical or other trials'.

In theory, the European Directive and the UK's 2004 Regulations only apply to research that involves clinical trials of investigational medicinal products, ${ }^{10}$ with the common law applies to other types of research. However, all research involving human participants falling within the remit of NHS research ethics committees (RECs) must be subjected to ethical scrutiny and receive the appropriate approvals before it can commence. This is significant for three reasons. First, the National Research Ethics Service (NRES), which oversees the operation of all NHS RECs, has adopted a policy that requires the standards contained in the UK's 2004 Regulations to be applied to all research, even non-clinical trials research. ${ }^{11}$ Secondly, with regard to consent and authorisation for a child's participation in research, this implies that RECs must follow the approach specified within those Regulations rather than the common law, which has serious implications for the autonomy of minors. ,Finally, because some aspects of those Regulations are at odds with established ethical guidance, the policy has the potential to cause confusion and misapprehensions in the research community and amongst members of RECs.

This paper considers the implications of the consent arrangements in the UK's 2004 Regulations for minors who would be regarded as competent to give their own consent to medical treatment under the common law. By comparing the consent provisions in the Regulations with those prevalent in ethical guidelines and the common law, it will demonstrate inconsistencies which are likely to have a detrimental impact on the autonomy of children involved in medical research. Alongside this, I also explore the legal and ethical status of the practice of obtaining a child's assent to participate in research and reveal worrying discrepancies between the law and ethics in this area.

\footnotetext{
${ }^{9}$ ibid, Article 1

${ }^{10}$ Defined in Regulation 2 of the UK's Clinical Trials Regulations as 'any investigation in human subjects...intended (a) to discover or verify the clinical, pharmacological or other pharmacodynamic effects of one or more medicinal products, (b) to identify any adverse reactions to one or more such products, or (c) to study absorption, distribution, metabolism and excretion of one or more such products, with the object of ascertaining the safety or efficacy of those products.'

${ }^{11}$ NRES, Standard Operating Procedures for Research Ethics Committees: version 4.0 April 2009, London: Department of Health, 2009: 9 available at: http://www.nres.npsa.nhs.uk/news-and-publications/publications/standard-operatingprocedures/\#Documents last accessed $1^{\text {st }}$ September 2009
} 


\section{Consent to children's participation in research - the law and ethics}

(i) Statutory authority

Respect for autonomy demands that consent should be obtained prior to conducting any research involving any human participants, regardless of whether they are adults or children. Consent also provides legal authorisation for any physical contact or the use of any data involved in the research process. Consent must be given by a person who has the capacity and authority to do so. To this end the law operates under the rebuttable presumption that adults have capacity to make their own decisions about treatment, research, or other aspects of social life, but that minors do not. ref Where medical interventions involving children are concerned consent is ordinarily given by an adult who has parental responsibility (PR) for the child until such time as a minor achieves maturity. Usually this means that the parents, ${ }^{12}$ some other person with PR or, occasionally, the courts will consent to the intervention until the child is old enough to decide for herself.

However, the age at which a person acquires legal decisionmaking capacity and can consent on her own behalf is rather imprecise. The Family Law Reform Act 1969 defines the age of majority in England and Wales as $18,{ }^{13}$ but with regard to beneficial medical treatment, section 8 permits 16 and 17 year olds to consent on their own behalf. In Scotland the Age of Legal Capacity (Scotland) Act 1991 sets the age at which one attains full decision-making capacity at 16 years. But the UK's 2004 Regulations define an "adult" as "a person who has attained the age of 16 years', ${ }^{14}$ whereas the 2006 EU Regulations state that "paediatric population" means that part of the population aged between birth and eighteen years'. ${ }^{15}$ Neither makes any provision for consent from competent minors.

(ii) Common law

In Gillick v West Norfolk and Wisbech Area Health Authority it was acknowledged that socially, as in nature, growing up is a

\footnotetext{
${ }^{12}$ The Children Act 1989 gives parents the right to do this in England and Wales, and in Scotland is reflected in the Children (Scotland) Act 1995. In Northern Ireland the Children (Northern Ireland) Order 1995 applies the same principles.

${ }^{13} \mathrm{~s} 1(1)$

${ }^{14}$ Regulation 2(1)

${ }^{15}$ European Regulation No 1901/2006 on medicinal products for paediatric use, Article 2(1)
} 
continuous process and that the law must be sensitive to human development and social change'. ${ }^{16}$ Accordingly, a minor under the age of 16 who has attained sufficient maturity may, in appropriate circumstances, lawfully consent to medical treatment on her own behalf. But Gillick concerns medical treatment and diagnosis that is regarded as in the best interests of the child, rather than research andThere are no specific cases pertaining to the validity of consent from competent minors in relation to research.

(iii) Ethical guidance

In the context of healthcare research, the vast majority of national and international ethical guidance favours an approach that maximises the autonomy of all potential research participants, including children. To this end, it has long been advised that, wherever possible, researchers should request and obtain the agreement of children being recruited into research studies. ${ }^{17}$ The Medical Research Council has adopted a more forthright stance arguing that 'where children have sufficient understanding and intelligence to understand what is proposed, it is their consent and not that of their parent/guardian that is required by law'. ${ }^{18}$ But he legal probity of this is now questionable, in view of the recent legislative changes noted above. The General Medical Council (GMC) is more reticent with regard to the status of children's consent and is closer to reflecting the legal position. It thus advises that where children are below the age of 18, even if they are 'able to consent for themselves' the doctor 'should still consider involving their parents, depending on the nature of the research'. ${ }^{19}$

(iv) International ethical guidance

The foundations of most domestic and professional ethical guidance on human participant research were laid down in the Declaration of Helsinki, first published in 1964 and subsequently revised, most recently in 2008. Its principles are at the centre of the EU Directive and the UK's 2004 Regulations. It is notable,

\footnotetext{
${ }^{16}$ Gillick $v$ West Norfolk and Wisbech Area Health Authority [1985] 3 All ER 402, 412 HL per Lord Fraser . To avoid any confusion it should be noted that the leading judgment in Gillick was delivered by Lord Fraser, hence the term 'Fraser competence' is sometimes substituted for the more usual 'Gillick competence'.

${ }^{17}$ Royal College of Paediatrics and Child Health: Ethics Advisory Committee, Guidelines for the Ethical Conduct of Research Involving Children. Archive of Diseases of Childhood 2000; 82: $177-186$

${ }^{18}$ MRC, Medical Research Involving Children London: MRC, 2004: 23, emphasis added.

${ }^{19}$ GMC, $0-18$ Years: Guidance to All Doctors London: GMC, 2007: paragraph 38. The GMC guidance on research is soon to be updated and is currently the subject of a public consultation
} 
however, that the latterpurport to incorporate the provisions contained in the Declaration of Helsinki as amended in 1996, rather than the more recent revisions. ${ }^{20}$ That version stipulates that when a 'minor child is in fact able to give consent, the minor's consent must be obtained in addition to the consent of the minor's legal guardian'. ${ }^{21}$ The most recent version of the Declaration does not distinguish minors from others who are unable to consent for themselves, but it does insist that 'no competent individual may be enrolled in a research study unless he or she freely agrees', (para. 22). This version of the Declaration also offers no guidance on what constitutes competence but, in relation to the ethical review of research proposals, insists that consideration must be had for the "laws and regulations of the country ... in which the research is to be performed' (para. 15). This introduces some ambiguity with regard to competent minors in the UK because these individuals may consent to medical treatment under Gillick, but are not recognised under the UK's 2004 Regulations. Given that earlier versions of the Declaration, including the one enshrined in the UK's 2004 Regulations, required consent to be given by competent minors, it would not seem unreasonable to assume that, ethically, minors who are demonstrably capable of deciding for themselves ought properly to fall within the auspices of paragraph 22 of the 2008 revision. However, this ethical imperative is absent from the UK's 2004 Regulations, and the approach adopted therein has important implications for the autonomy of competent minors in relation to healthcare research.

\section{Legal standards and ethical best practice - the UK's 2004 Regulations}

Under Schedule 1 Part 4 paragraph 13 of the UK's 2004 Regulations, 'the informed consent of the parents or legal representative' must be obtained to authorise the participation of a minor in a clinical trial. ${ }^{22}$ Where very young children are involved this is clearly appropriate and is in line with the law on consent to the medical treatment of children. It is, however, at odds with most of the ethical guidance pertaining to the involvement of children in research, and with the common law relating to the right of Gillick

\footnotetext{
${ }^{20}$ Clinical Trials Regulations, Schedule 1 Part 2 paras 1 and 2

${ }^{21}$ Paragraph I.11 of the 1996 revision. The Declaration of Helsinki has been revised six times since 1964, and twice since 1996, most recently in Seoul in October 2008. Notes of clarification on paragraphs 29 and 30 were added in 2002 and 2004 respectively. The full Declaration is available at http://www.wma.net/e/policy/b3.htm last accessed 1st September 2009

${ }^{22}$ And, by extrapolation, all other research reviewed by NHS RECs
} 
competent, mature minors to consent to medical treatment on their own behalf. And, it is not only in this regard that the ethics and law surrounding children's involvement in research diverge.

Alongside the authorisation of parental proxy consent the UK's 2004 Regulations stipulate that the 'informed consent given by a person with parental responsibility or a legal representative to a minor taking part in a clinical trial shall represent the minor's presumed will'. ${ }^{23}$ So, not only is there no provision for the child to decide for herself, even if competent to do so, but there seems to be an in-built assumption of agreement between parent and child. This is disrespectful of the competent minor's autonomy to deny them the opportunity, if not the right, to participate in the decisionmaking process, but it is also unrealistic to assume that every minor is accepting of and compliant with the views of their parent or representative. For these reasons, ethical best practice, as enshrined in the majority of guidelines from professional bodies and research councils, ${ }^{24}$ advise that even if a child cannot give a legally valid and binding consent, their assent should be obtained before they are enrolled into a research study.

The European Clinical Trials Directive itself is silent on the issue of children's assent, although its significance was recognised and defined 'in the context of Article 4(c) of the Clinical Trials Directive', as, 'the expression of the minor's will to participate in a clinical trial'. ${ }^{25}$ Obtaining the assent of those who lack the legal capacity to give a valid consent is an important acknowledgment of their individual autonomy and self-determination. As such it is pivotal to the ethical conduct of research. Yet not only do the UK's 2004 Regulationsfail to incorporate any mechanism for the competent minor to give consent, they are also silent on the issue of assent.

Schedule 1, Part 4 paragraph 6 of the UK's 2004 Regulations does include the requirement that the minor will be furnished with information about the trial and its risks and benefits, 'according to his capacity of understanding, from staff with experience with

${ }^{23}$ Clinical Trials Regulations, Schedule 1 Part 4 paragraph 13. This exactly mirrors Article 4(a) of the EU Directive.

${ }^{24}$ Including paragraph 28 of the World Medical Association's Declaration of Helsinki 2008. Any more examples?

${ }^{25}$ Recommendations of the Ad hoc group for the development of implementing guidelines for Directive 2001/20/EC relating to good clinical practice in the conduct of clinical trials on medicinal products for human use, Ethical Considerations for Clinical Trials on Medicinal Products with the Paediatric Population, 2008 Available at http://ec.europa.eu/enterprise/pharmaceuticals/eudralex/vol-10/ethical considerations.pdf last accessed 1st September 2009, chapter 5.7 p8. Emphasis supplied. 
minors': a provision which could be regarded as a recognition of the autonomy of the minor research participant. However, in the context of the Regulations it appears to be aimed more at ensuring that research is conducted by properly trained and experienced staff, rather than at enhancing the autonomy of child participants. That said, under the next paragraph in the Regulations one of the conditions and principles which must be satisfied before research involving minors can be conducted is that:

The explicit wish of a minor who is capable of forming an opinion and assessing the information ... to refuse participation in, or to be withdrawn from, the clinical trial at any time is considered by the investigator. ${ }^{26}$

Although this is to be read in conjunction with the fact that the minor has been given information about the trial and its implications, and could be read as promoting the participant's autonomy, it actually falls short. The absence of any requirement to do more than merely consider a minor's explicit wish to be withdrawn, or indeed not to participate at all, clearly fails to respect the minor's autonomy. It is also out of step with most ethical guidance. For example, the GMC advises that children 'should not usually be involved in research if they object or appear to object in either words or actions, even if their parents consent', ${ }^{27}$ which represents a clear acknowledgement of the significance that ought to be placed on the child's views in these circumstances. A similar precept appears in the influential guidance published by the Council for International Organisations of Medical Sciences (CIOMS), which insists that 'a child's refusal to participate in the research will be respected' ${ }^{28}$ Ethically then, active dissention from a child who refuses to participate in the research, or wishes to be withdrawn from it, should be acted upon, and not merely 'considered'. The failure of the UK's 2004 Regulations to reflect such provisions is detrimental to children's rights to autonomy, especially in the case of competent minors.

In a healthcare environment where individual autonomy is widely championed one might expect that gaining the agreement of

\footnotetext{
${ }^{26}$ Schedule 1, Part 4, paragraph 7 of the 2004 Regulations, emphasis added.

${ }^{27}$ General Medical Council, 0-18 Years: Guidance to All Doctors. London: GMC, 2007: paragraph 38

${ }^{28}$ ClOMS, International Ethical Guidelines for Biomedical Research Involving Human Subjects. 2002: Guideline 14, available http://www.cioms.ch/frame guidelines nov 2002.htm last accessed 1st September 2009
} 
competent minors to their participation in research would be regarded as a crucial aspect of the regulatory regime. This is particularly so because a central principle of the UK's 2004 Regulations is the requirement that, "the clinical trial has been designed to minimise pain, discomfort, fear and any other foreseeable risk in relation to the disease and the minor's stage of development." ${ }^{29}$ Aside from the appeal to autonomy, involving the minor in the consent process would seem an obvious way to minimise, fear and emotional, if not physical, discomfort. But, instead, the parent or person with PR is given absolute power and complete authority to represent the 'presumed will' of the child regardless of the age or experience of the minor.

\section{Conclusions}

There are thus a number of tensions between the law and ethical guidance in relation to research involving competent minors. The latter suggests, indeed requires, that children should be included in any decision about whether to participate in research, but the legal regulation of research makes no provision for their consent or assent to be obtained. This tension is exacerbated by the fact that NRES policy requires NHS RECs to treat all research they review according to the standards in the UK's 2004 Regulations, even that which does not involve pharmaceutical products or medical devices. As a consequence, the autonomy of competent minors may be severely compromised, and inconsistency and confusion is likely to be caused in the process of ethical review. More specifically, RECs may opt to adhere to the UK's 2004 Regulations in relation to clinical trials research but, contrary to NRES guidelines, decide to follow ethical and professional guidance otherwise. The result will be a double standard whereby the level of respect for the autonomy of competent minors becomes dependent on the kind of research they participate in. This position is unethical and also out of step with practices in other, comparable, jurisdictions, such as the US where it is expected that researchers will at least seek assent from children above the age of seven. ${ }^{30}$ Denying children the opportunity, if not the right, to participate in the decision about whether to be involved in research is overly paternalistic, particularly with regard to competent minors.

\footnotetext{
${ }^{29}$ Schedule 1, Part 4, paragraph 14

30 Singh I, Capacity and Competence in Children as Research Participants, European Molecular Biology Organization Journal 2007; 8: 35-39
} 
As Sarah Elliston has argued, the ethical approach that maximises child and adolescent autonomy is far preferable, and where a competent minor wishes to make the decision she 'should be at liberty to do so'. ${ }^{31}$ There are now so many safeguards to protect the interests of research participants that, so long as the research is scientifically sound and has ethical approval, a competent minor who is capable of understanding the implications of their participation should be permitted to give their own informed consent, and that consent ought to be authoritative. Some commentators go one step further arguing that where a minor is competent to give consent, not only should she be trusted to make self-interested decisions, but should also be permitted to act altruistically for the benefit of others. ${ }^{32}$ Moreover, where the minor is not capable of providing a legal consent, parental consent should be obtained, and deemed legally valid only where the child's assent is forthcoming.

Yet the UK's 2004 Regulations do not require consent or assent from minors, and this offends all ethical guidelines pertaining to children and research. It is also counter to the central premise of research ethics which dictates that no competent person should be expected to participate in research without first giving their voluntary, informed consent. Whilst it is understandable to seek to avoid exploitation of a population as vulnerable as children, it must be recognised that competent minors are just that; competent and capable of making their own informed decisions. The present position means that the autonomy of competent minors participating in healthcare research is better protected by nonenforceable ethical guidelines than it is by the law. In a research arena dominated by individual autonomy and self-determination that is most certainly not okay.

\footnotetext{
${ }^{31}$ Elliston S, The Best Interests of the Child in Healthcare. London: Routledge-Cavendish, 2007: 193

${ }^{32}$ Baylis F, Downie J, The limits of altruism and arbitrary age limits. The Americal Journal of Bioethics, 3:4, 2003, 19.
} 